\title{
Hypothesized mechanisms through which acute exercise influences episodic memory
}

\author{
PD Loprinzi, P Ponce, E Frith \\ Exercise \& Memory Laboratory, Department of Health, Exercise Science and Recreation Management, \\ The University of Mississippi, Oxford, MS, USA
}

Received: May 17, 2018

Accepted: November 15, 2018

\begin{abstract}
Emerging research demonstrates that exercise is favorably associated with several cognitive outcomes, including episodic memory function. The majority of the mechanistic work describing the underlying mechanisms of this effect has focused on chronic exercise engagement. Such mechanisms include, e.g., chronic exercise-induced neurogenesis, gliogenesis, angiogenesis, cerebral circulation, and growth factor production. Less research has examined the mechanisms through which acute (vs. chronic) exercise subserves episodic memory function. The purpose of this review is to discuss these potential underlying mechanisms, which include, e.g., acute exercise-induced (via several pathways, such as vagus nerve and muscle spindle stimulation) alterations in neurotransmitters, synaptic tagging/ capturing, associativity, and psychological attention.
\end{abstract}

Keywords: cognition, exercise, pathways, hippocampus, memory

\section{Introduction}

Emerging research demonstrates that exercise engagement can improve cognitive function $(15,25,35,50,52,89)$, and this relationship may even be bidirectional $(51,69)$. To date, much of the mechanistic work has focused on chronic exercise behavior and its ability to induce neurogenesis, gliogenesis, angiogenesis, cerebral circulation, and growth factor production $(8,28,29,31,40,42)$. Of interest herein are the mechanisms of acute exercise on episodic memory function.

The purpose of this study is to discuss the mechanistic effects of acute exercise on episodic memory function (50), or the recall of past events based on a temporal-spatial context. Emerging work, indeed, demonstrates that acute exercise may subserve episodic memory function (50). We recently detailed various potential mechanisms of exercise on episodic memory function (47). These postulated exercise-related mechanisms include, e.g., (1) exercise enhancing neuronal excitability; (2) exercise enhancing attentional resource allocation to facilitate memory encoding; (3) exercise upregulating $\alpha$-amino-3-hydroxy5-methyl-4-isoxazolepropionic acid receptor levels, opening N-methyl-D-aspartate (NMDA) channels, and increasing excitatory post-synaptic potentials (EPSPs) in the hippocampus; (4) exercise priming neurons to be encoded in the memory trace by increasing cAMP response element binding (CREB) transcription; (5) brain-derived neurotropic factor (BDNF)

Corresponding author: Paul D. Loprinzi, $\mathrm{PhD}$

Exercise \& Memory Laboratory, Department of Health, Exercise Science, and Recreation Management, School of Applied Sciences, The University of Mississippi

229 Turner Center, University, Oxford, MS 38677, USA

Phone: +1 662915 5521; Fax: +1 662915 5525; E-mail: pdloprin@olemiss.edu 
expression from exercise; and (6) exercise enhancing dendritic spine growth. Regarding BDNF, recent research highlights the key role of BDNF in potentially mediating the relationship between exercise and memory (48). For example, exercise-induced increases in BDNF may promote neuronal survival, increase intracellular calcium levels, facilitate transcription factors, and induce mTOR-mediated mRNA translation for memory consolidation $(48,82)$.

\section{Muscle Spindle Pathway}

The distinction of this present review is the explicit focus on "acute" exercise and its unique effects on influencing episodic memory function. The heart of this paper is the effects of acute exercise on long-term potentiation (LTP), or the functional connectivity between neurons. LTP is considered a key mechanism subserving episodic memory function $(38,87)$. We hypothesize that acute exercise induces near immediate effects on neuronal excitability using one of two major pathways. First, contraction of the skeletal muscles will activate the respective muscle spindles, and in turn, generate action potentials that are transmitted by afferent peripheral nerves to the dorsal spinal cord and then to the brain stem (Fig. 1). In the brain stem, activation of the nucleus of the tractus solitaries (NTS) [and by extension, locus coeruleus (LC)] has projections to the prefrontal cortex and basolateral amygdala, both of which are implicated in memory function $(71,74)$. In addition, the LC has direct projections to the dentate gyrus, CA3, and CA1 hippocampal structures $(32,60)$. We assume that these anatomical connections will allow for functional connectivity to occur, but of course, anatomical connections do not always imply that a functional association is going to occur.

\section{Vagus Nerve Pathway}

We hypothesize that another acute exercise-induced hippocampal neuronal pathway involves activation of the vagus nerve (Fig. 2), which may occur from various routes, including activating various tissues (e.g., lungs) or exercise-induced increases in catecholamines (e.g., epinephrine). The vagus nerve is the longest cranial nerve in the body, comprised approximately $80 \%$ afferent fibers and $20 \%$ efferent fibers (23). The afferent sensory fibers relay information from various peripheral tissues (e.g., respiratory tract and heart) to the NTS. As noted above, activation of the NTS has projections to the LC, which in turn has a direct connection with the CA1 structure $(12,60)$.

The hippocampal CA1 structure has been extensively studied under the context of hippocampal LTP (Fig. 3) (9). Figure 3 demonstrates a brief schematic representation illustrating components of early (E-LTP) and late-phase LTP (L-LTP). For a more thorough discussion, see other reviews $(47,56,67)$. Importantly, in the context of acute exercise, within 10 min after the induction of LTP, outgrowth of new pre- and post-synaptic processes has been observed $(21,53,65)$. Moreover, even within minutes after LTP, studies have observed increases in spine size (55), clustering of post-synaptic glutamate receptors (81), and clustering of pre-synaptic vesicle-associated proteins and colocalizing of pre- and postsynaptic sites (5).

Through the vagus nerve, brain stem stimulation can increase various memory-related neurotransmitters in the Cornu Ammonis region, including norepinephrine (NE; coming from the LC), dopamine (DA; coming from the LC, substantia nigra, and ventral tegmental area), 


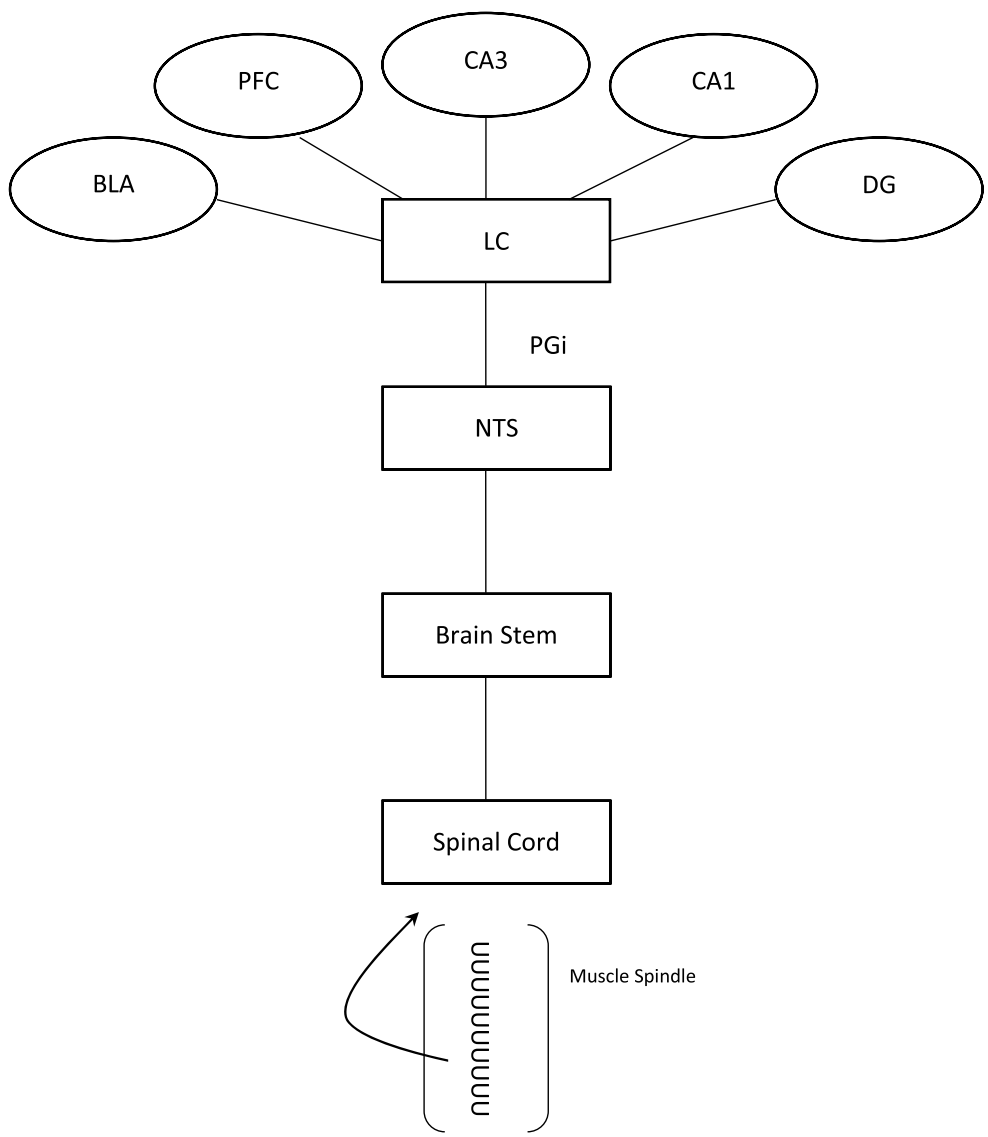

Fig. 1. Muscle spindle pathway. Contraction of the skeletal muscle activates the muscle spindle, generating an action potential that is transmitted by peripheral nerves to the spinal cord, and then to the brain stem. Then, in the brain stem, activation of the NTS can facilitate production of neurotransmitters in the LC, which has projections to several hippocampal (CA3, CA1, and DG) and non-hippocampal memory-related structures (BLA and PFC). BLA: basolateral complex of the amygdala; DG: dentate gyrus; LC: locus coeruleus; NTS: nucleus tractus solitarius; PGi: nucleus paragigantocellularis; PFC: prefrontal cortex

serotonin (5HT; coming from the raphe nuclei in the brain stem), and acetylcholine (ACh; coming from the medial septal nucleus) (Fig. 4).

\section{Neurotransmitter Mediation}

The mechanistic actions of neurotransmitters in influencing the exercise-memory interaction are of great interest $(57,59)$. Regarding NE, there are three types of metaboreceptors that NE binds to, including $\beta\left(\beta_{1}, \beta_{2}\right.$, and $\left.\beta_{3}\right), \alpha 1$, and $\alpha 2$ (54). The majority of the research on memory function demonstrates that NE induces LTP through $\beta$-receptors. Triggering these receptors activates adenylate cyclase and produces cyclic adenosine monophosphate (cAMP), which, in turn, is associated with CREB protein activation (54). Furthermore, NE-facilitated $\beta$-receptor activation can augment LTP through protein kinase A (PKA) activation (93). 


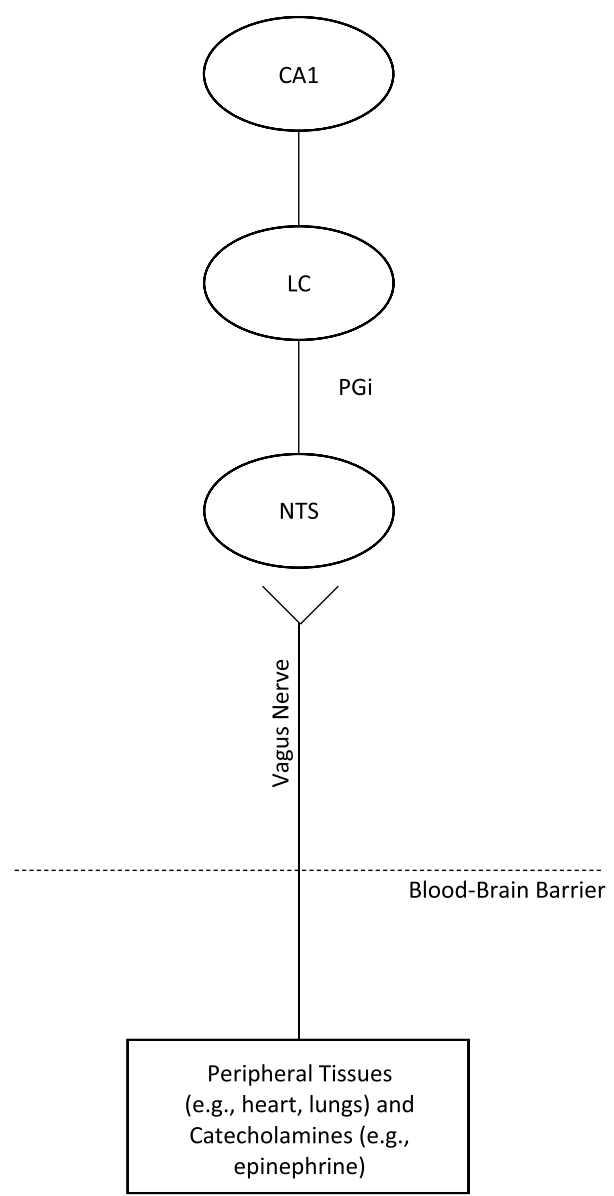

Fig. 2. Vagus nerve pathway. Afferent sensory fibers relay information from various peripheral tissues to the NTS. Activation of the NTS has projections to the LC, which has direct connections to the CA1 hippocampal structure. LC: locus coeruleus; NTS: nucleus tractus solitarius; PGi: nucleus paragigantocellularis

Specific details on the role of these proteins on LTP have been discussed elsewhere (47). It is clear that NE plays a critical role in hippocampal LTP $(33,37,85)$, with research providing evidence that exercise can increase NE levels $(79,92)$.

Although inconsistent (90), some evidence suggests that exercise increases levels of DA (86). Through D1-like $\left(\mathrm{D}_{1} / \mathrm{D}_{5}\right)$ DA receptors, sequential activation of adenylate cyclase $\left[\mathrm{D}_{1}\right.$ through PKA and $\mathrm{D}_{5}$ through protein kinase $\left.\mathrm{C}(26)\right]$ and cAMP may ensue (DA also binds to inhibitory-type receptors, $\mathrm{D}_{2}, \mathrm{D}_{3}$, and $\mathrm{D}_{4}$ ) (64). Furthermore, DA signaling may help mediate memory trace formation (63) by influencing aspects of LTP [e.g., NMDA phosphorylation via the PKA pathway (84)] (70), as well as metaplastic control over LTP and long-term depression (80). DA receptor activation in the CA1 also initiates processes related to the synthesis of plasticity-related proteins (PRPs; discussed later) that may be involved in setting and stabilizing the synaptic tag $(43,77)$. Indeed, in human studies, and in a dosedependent inverted U-shaped pattern, DA has been shown to enhance recollection of neutral memory (14), highlighting its critical role in synaptic connections and memory consolidation.

5HT may also play a significant role in hippocampal LTP (61). Moreover, it seems that 5HT release may be stress-specific, with acute exercise stress-triggering augmented 5-HT release (and acting on various receptors, including $5-\mathrm{HT}_{1 \mathrm{a}}, 5-\mathrm{HT}_{1 \mathrm{~b}}, 5-\mathrm{HT}_{2 \mathrm{a}}, 5-\mathrm{HT}_{2 \mathrm{c}}, 5-\mathrm{HT}_{3}$, 

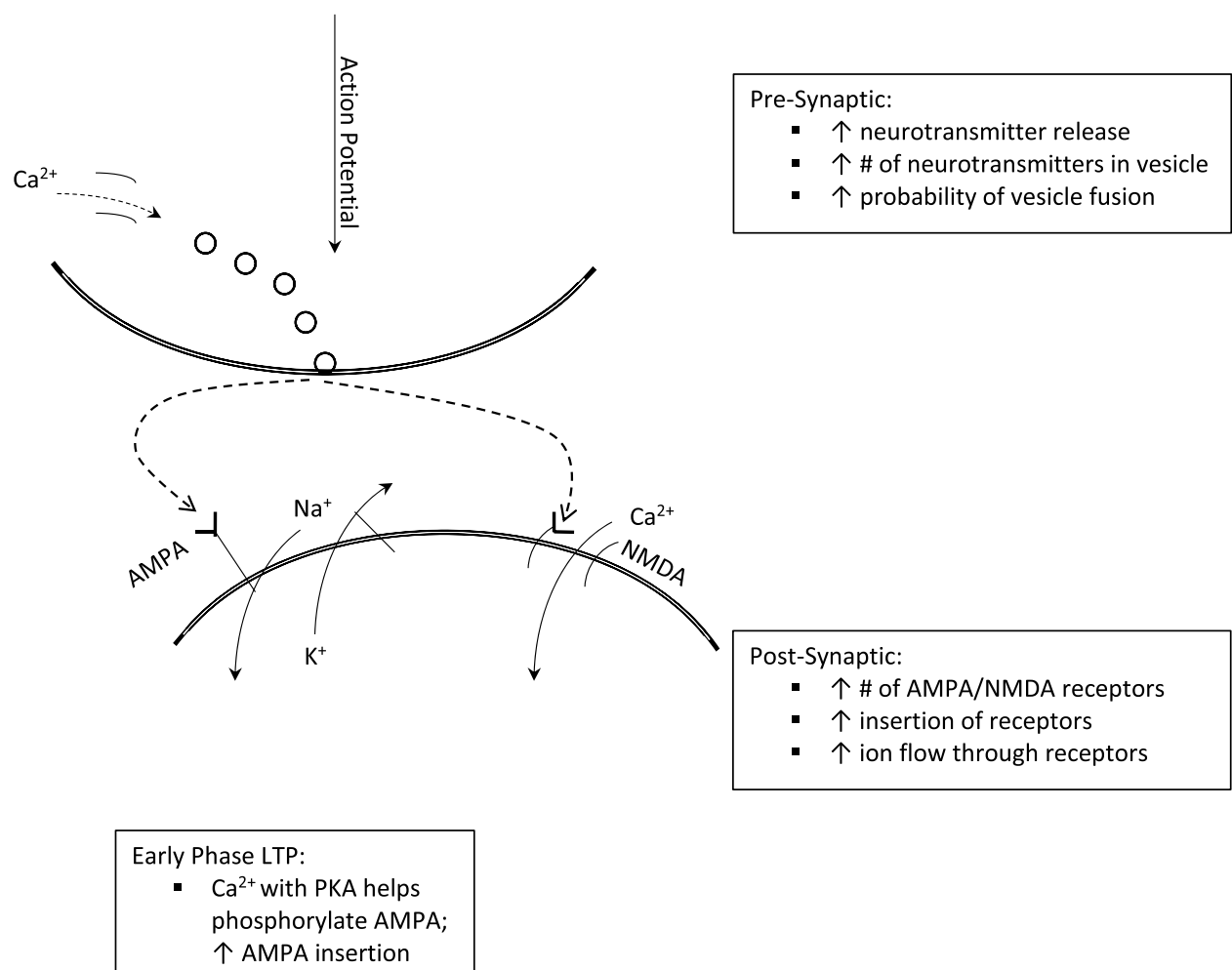

- $\mathrm{Ca}^{2+}$ uptake activates CAMP, activating CREB

- Gene expression to $\uparrow$ synaptic plasticity

Fig. 3. Schematic representation of LTP illustrating pre- and post-synaptic changes. Pre-synaptic action potential increases $\mathrm{Ca}^{2+}$ influx, facilitating vesicle docking. Neurotransmitter (e.g., glutamate) binds to AMPA receptor, facilitating $\mathrm{Na}^{+}$influx and $\mathrm{K}^{+}$efflux, inducing cell depolarization. $\mathrm{Ca}^{2+}$ enters NMDA through electrostatic repulsion, which phosphorylates AMPA receptors through protein kinases. Late-phase LTP involves $\mathrm{Ca}^{2+}$-activating pathways that upregulate transcription factors to facilitate synaptic plasticity

$5-\mathrm{HT}_{4}, 5-\mathrm{HT}_{5}, 5-\mathrm{HT}_{6}$, and 5- $\mathrm{HT}_{7}$ ) and turnover in the amygdala, via rapid consolidation of memories promoted by efficient neural transitions from E-LTP to L-LTP (2). Activation of the $\mathrm{G} \alpha_{\mathrm{s}}$-coupled receptor leads to the stimulation of adenylate cyclase, elevating cAMP, and in turn, activating PKA (10). This phosphorylating enzyme can then activate CREB-modifying gene expression. Indeed, recent work demonstrates that exercise can increase 5-HT levels, which may mediate memory enhancement effects (68).

In addition to the aforementioned neurotransmitters (NE, DA, and 5HT), ACh also plays an important role in hippocampal-dependent learning and memory (34). Acting on muscarinic cholinergic receptors (ACh also binds to nicotinic receptors), increases in ACh have been shown to enhance hippocampal CA1 LTP (66), with this effect being greatest during walking, as opposed to other behavioral scenarios (awake-immobility, slow-wave sleep, and 


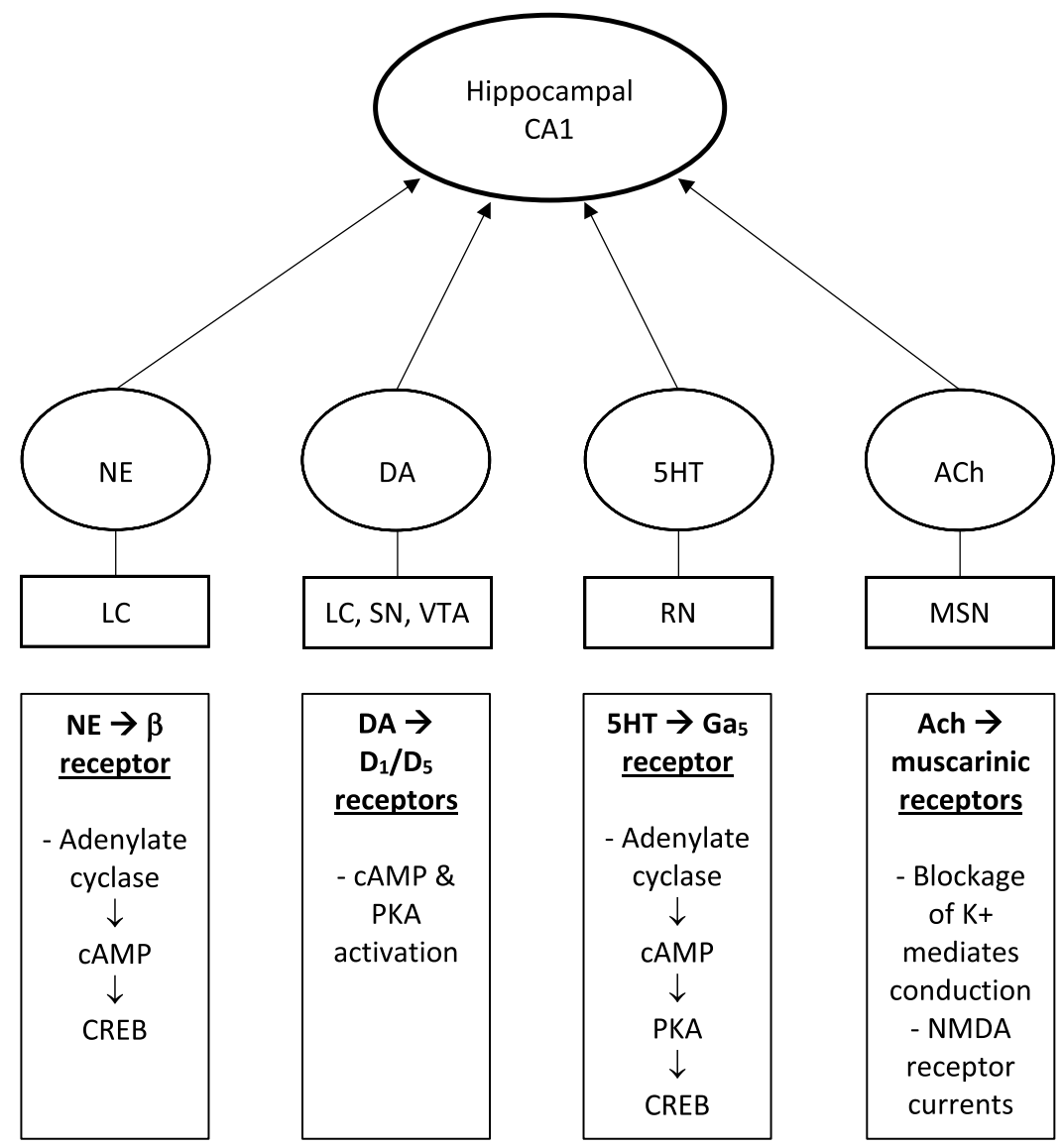

Fig. 4. Neurotransmitter mediation of hippocampal CA1, illustrating potential mechanisms through which these neurotransmitters influence CA1 LTP. 5HT: serotonin; ACh: acetylcholine; DA: dopamine; LC: locus coeruleus; MSN: medial septal nucleus; NE: norepinephrine; RN: raphe nuclei; SN: substantia nigra; VTA: ventral tegmental area

rapid eye movement sleep) (44). Mechanisms of this effect may be a result of blockage of $\mathrm{K}^{+}$mediated conductances and enhancement of NMDA receptor currents (44). Recent work also demonstrates that exercise may increase ACh levels, potentially mediating improvements in memory function (18).

Thus, acute exercise may induce hippocampal neuronal excitability via afferent muscle spindle activation (Fig. 1) as well as from vagus nerve stimulation arising from afferent inputs in the lungs and heart (Fig. 2). This, in turn, induces various neurotransmitters (NE, DA, 5HT, and ACh) in the CA1 structure (Fig. 4), facilitating LTP (Fig. 3), or the continuous release of neurotransmitters to sustain EPSP. We believe that these sustained EPSPs constitute a critical mechanism through which acute exercise may influence episodic memory function.

\section{Synaptic Tagging and Capturing}

In addition to these potential acute exercise-memory mechanisms (Figs 1-4), we also hypothesize that acute exercise may facilitate episodic memory through synaptic tagging 


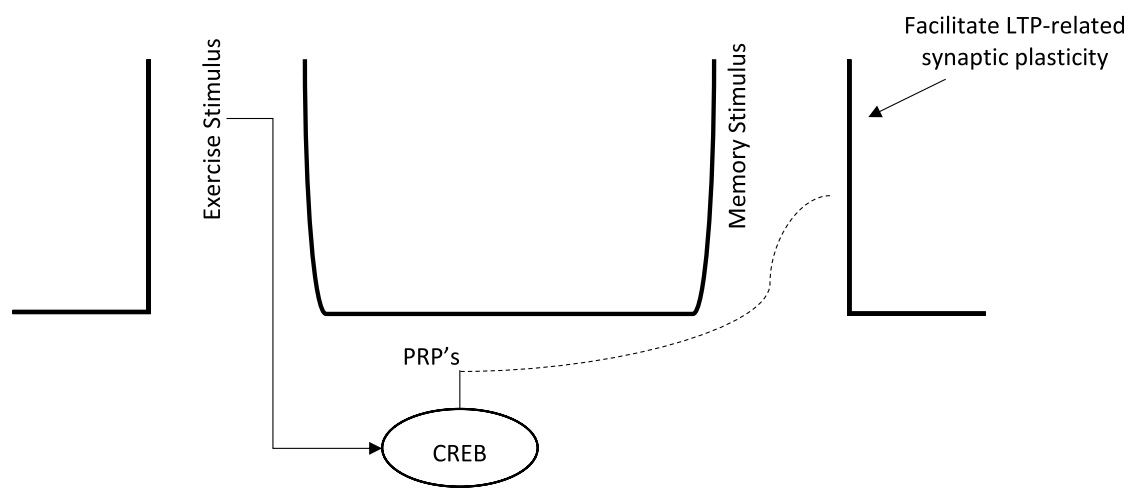

Fig. 5. Synaptic tagging and capturing. The exercise stimulus triggers plasticity-related proteins (PRPs) that tag another synapse, captured by the memory stimuli. This helps facilitate long-term potentiation (LTP) at the memory synapse. CREB: cAMP response element binding

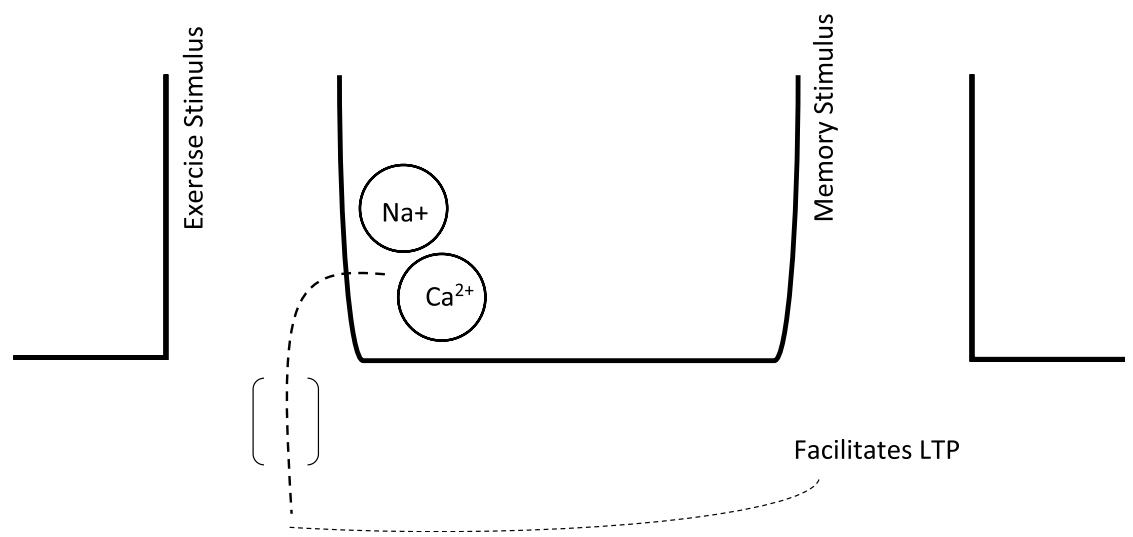

Fig. 6. Schematic representation of associativity effects. The acute bout of exercise may induce a high action potential. This increased accumulation of sodium and calcium ions may leak over and induce potentiation of the memory trace, facilitating long-term potentiation (LTP) of the pre-synaptic-post-synaptic memory stimulus neuron. Relatedly, this action potential may induce a dendritic spike (neural backpropagation), facilitating depolarization of the synapse of the memory stimulus, ultimately priming NMDA-mechanisms to facilitate LTP

(Fig. 5) and associativity effects (Fig. 6) (7). The concept of synaptic tagging and capture and its influence on LTP were introduced by Frey and Morris (24). Traditionally, behavioral tagging refers to the conversion of a short-term weak memory to a stable long-term memory because of its proximity to a strong memory. A short-term memory, triggered by E-LTP-inducing synaptic inputs, can be stabilized by a stronger memory trigger. Specifically, the stronger memory triggers PRPs that can help to rescue the weaker memory. The PRPs, produced via CREB mechanisms, travel from the cell body of one neuron to other synapses, facilitating LTP at that synapse. We hypothesize that exercise produces synaptic PRPs, with the subsequent memory stimuli capturing this tag (Fig. 5). In this context, we view acute exercise as a metaplasticity phenomenon, which develops when an initial priming event (e.g., acute exercise) induces physiological/biochemical changes in neurons/synapses that modulate plasticity induced by a subsequent event (e.g., memory stimuli) (1). 
There are several studies to support this hypothesis. Moncada and Viola (62) and Ballarini et al. (6) were the first to design studies to evaluate the possibility of an interaction between unrelated tasks that rely on hippocampal plasticity that could be explained by synaptic tagging and capturing. These studies exposed rats to an open field (novel environment) for $5 \mathrm{~min}$, which served as the task to elicit the PRPs, followed by a weak-learning task (that induces short, but not long-term memory) that is presumably tagged. Mancoda and Viola (62) showed that the exposure to the open field (1 h prior) helped to consolidate the short-term memory into a long-term memory, which depended on activation of $\mathrm{DA} \mathrm{D}_{1} / \mathrm{D}_{5}$ receptors. Thus, the open field exploration provided the PRPs, via behavioral tagging, to stabilize the memory trace. Similarly, Almaguer-Melian et al. (3) found that a 5-min exposure to a novel open field 15-min before or after the water-maze training favored spatial learning. They showed that this open field exposure reversed the deleterious effect of post-training foot shock on learning, through a protein synthesis-dependent process. Thus, this study demonstrates that novelty-induced PRPs are able to prevent the memory disruption caused by stress, and that the stress does not interfere with either the tag-setting or tag-capturing processes.

\section{Associativity}

Another plausible neuronal-related mechanism through which acute exercise may influence episodic memory function is through an associativity effect (45). As schematically displayed in Fig. 6, if the acute bout of exercise occurs around the same time (e.g., shortly before) as the memory stimulus, it is possible that it may help to facilitate the stabilization of the memory trace, via LTP-related mechanisms. As an example, and as shown in Fig. 6, the two pathways (exercise and memory stimuli) involve a combination of a weak and strong input. Associativity is observed when the weak input is activated around the same time as the strong input, which induces LTP of the weak and strong pathways. Speculatively, the acute bout of exercise (strong input) may induce a high action potential, activating the memory trace. The increased accumulation of post-synaptic sodium and calcium ions, e.g., may leak over and induce potentiation of the memory trace and thus induce LTP of the pre-synapticpost-synaptic memory stimulus neuron. Relatedly, this action potential may induce a dendritic spike (neural backpropagation), facilitating depolarization of the synapse of the memory stimulus, ultimately priming NMDA mechanisms to facilitate LTP (11).

\section{Cognition Attention}

Another likely mechanism through which acute exercise may enhance episodic memory is through arousal/attentive effects (Fig. 7) $(4,58)$. Psychological attention may be viewed as three independent, yet interrelated systems, including alerting (readiness to receive the stimulus), orienting (directing attention to target stimulus), and executive control (management of mental resources to focus and inhibit conflicting stimuli) (27). Furthermore, as detailed elsewhere (22), attentional processes may involve involuntary or bottom-up attention, as well as voluntary or top-down attention.

Bottom-up attention may arise from the self-organized behavior of neuronal engram ensembles. After a sensory stimulus is presented, neurons that are sensitive to that stimulus are self-activated. Neurons within this ensemble that receive a transitory "superthreshold" stimulus will continue to fire if they are activated by another source of excitatory 


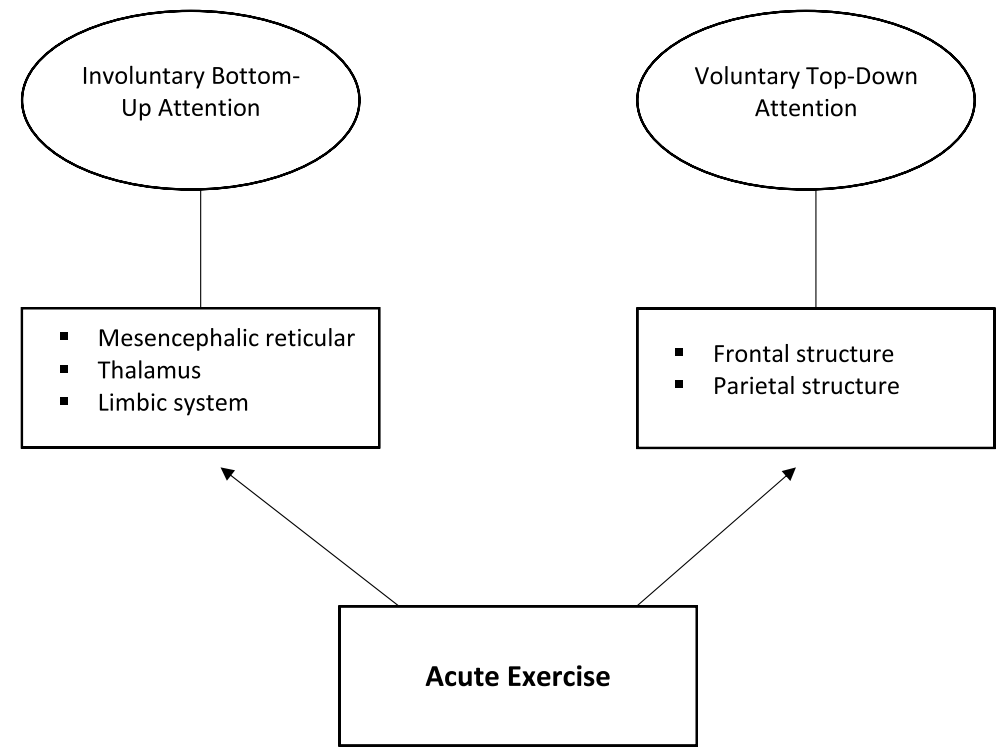

Fig. 7. Schematic representation of acute exercise attention. Acute exercise activates neuronal ensembles in the mesencephalic reticular formation, thalamus, and limbic structures to facilitate bottom-up attention. Acute exercise induces neuronal activation in the prefrontal and parietal structures to subserve top-down attention

input - either through arousal or affective reinforcement. (22) Structures involved in this arousal-induced excitatory input include the mesencephalic reticular formation and thalamus $(39,78)$, with the limbic system involved in the affective reinforcement stimuli (72). Notably, acute exercise has been shown to induce neuronal excitation in the mesencephalic reticular formation $(19,36)$, thalamus (73), and limbic structures (91), providing suggestive evidence that acute exercise may help to facilitate bottom-up attentional processes.

Voluntary, or top-down attention, involves several cortical areas, including the frontal and parietal structures $(16,17)$, which integrate feedback from neuronal assemblies of the bottom-up structures (reticular formation, thalamus, and limbic system) (22). Thus, top-down attention is a higher-order process involving the interaction of complex, dynamic brain structures. Acute exercise may help to facilitate top-down attention via increases in neuronal activity in both the frontal and parietal structures $(20,88)$.

\section{Conclusions}

Chronic exercise training may help to facilitate improvements in cognition (including memory) due to various exercise-induced mechanisms, such as neurogenesis, gliogenesis, angiogenesis, cerebral circulation, and growth factor production $(8,28,29,31,40,42)$. Here, we specifically discuss potential underlying mechanisms through which acute exercise may influence episodic memory function. Such mechanisms may include, e.g., acute exerciseinduced (via several pathways, such as vagus nerve and muscle spindle stimulation) alterations in neurotransmitters, synaptic tagging/capturing, associativity, and psychological attention. Although not within the scope of this review, future work should continue the discussion on whether acute exercise of varying intensities plays a differential role in these mechanisms, and in turn, episodic memory function $(30,46,50,75,94)$. Such an exploration 
will require careful consideration, given that exercise intensity may have a differential response on various parameters (e.g., cortisol) that may facilitate or potentially hinder episodic memory function $(13,49)$. In addition, our hypothesized models assume the acute bout of exercise occurs shortly before the episodic memory stimulus; thus, alterations in the temporality of the exercise and memory stimuli may result in unique mechanisms of this relationship $(25,41,76,83)$. Future work should thoroughly evaluate these models, which can be updated and revised as required.

\section{Acknowledgements}

The authors have no conflicts of interest and no funding was used to prepare this manuscript.

\section{REFERENCES}

1. Abraham WC, Bear MF: Metaplasticity: the plasticity of synaptic plasticity. Trends Neurosci. 19, 126-130 (1996)

2. Ahmed T, Frey JU, Korz V: Long-term effects of brief acute stress on cellular signaling and hippocampal LTP. J. Neurosci. 26, 3951-3958 (2006)

3. Almaguer-Melian W, Bergado-Rosado J, Pavon-Fuentes N, Alberti-Amador E, Merceron-Martinez D, Frey JU: Novelty exposure overcomes foot shock-induced spatial-memory impairment by processes of synaptic-tagging in rats. Proc. Natl. Acad. Sci. U. S. A. 109, 953-958 (2012)

4. Alves CR, Tessaro VH, Teixeira LA, Murakava K, Roschel H, Gualano B, Takito MY: Influence of acute highintensity aerobic interval exercise bout on selective attention and short-term memory tasks. Percept. Mot. Skills. $118,63-72(2014)$

5. Antonova I, Arancio O, Trillat AC, Wang HG, Zablow L, Udo H, Kandel ER, Hawkins RD: Rapid increase in clusters of presynaptic proteins at onset of long-lasting potentiation. Science 294, 1547-1550 (2001)

6. Ballarini F, Moncada D, Martinez MC, Alen N, Viola H: Behavioral tagging is a general mechanism of longterm memory formation. Proc. Natl. Acad. Sci. U. S. A. 106, 14599-14604 (2009)

7. Barco A, Lopez de Armentia M, Alarcon JM: Synapse-specific stabilization of plasticity processes: the synaptic tagging and capture hypothesis revisited 10 years later. Neurosci. Biobehav. Rev. 32, 831-851 (2008)

8. Barnes JN: Exercise, cognitive function, and aging. Adv. Physiol. Educ. 39, 55-62 (2015)

9. Bartsch T, Dohring J, Rohr A, Jansen O, Deuschl G: CA1 neurons in the human hippocampus are critical for autobiographical memory, mental time travel, and autonoetic consciousness. Proc. Natl. Acad. Sci. U. S. A. 108, 17562-17567 (2011)

10. Berumen LC, Rodriguez A, Miledi R, Garcia-Alcocer G: Serotonin receptors in hippocampus. ScientificWorldJournal 2012, 823493 (2012)

11. Carlson NR, Birkett MA (2017): Learning and memory. In: Physiology of Behavior, eds Carlson NR, Birkett MA, Pearson Education, Boston, p. 442

12. Castle M, Comoli E, Loewy AD: Autonomic brainstem nuclei are linked to the hippocampus. Neuroscience 134, 657-669 (2005)

13. Chen C, Nakagawa S, An Y, Ito K, Kitaichi Y, Kusumi I: The exercise-glucocorticoid paradox: how exercise is beneficial to cognition, mood, and the brain while increasing glucocorticoid levels. Front. Neuroendocrinol. 44, 83-102 (2017)

14. Chowdhury R, Guitart-Masip M, Bunzeck N, Dolan RJ, Duzel E: Dopamine modulates episodic memory persistence in old age. J. Neurosci. 32, 14193-14204 (2012)

15. Crush EA, Loprinzi PD: Dose-response effects of exercise duration and recovery on cognitive functioning. Percept. Mot. Skills. 124, 1164-1193 (2017)

16. Daffner KR, Scinto LF, Weitzman AM, Faust R, Rentz DM, Budson AE, Holcomb PJ: Frontal and parietal components of a cerebral network mediating voluntary attention to novel events. J. Cogn. Neurosci. 15, 294-313 (2003)

17. Dehaene S, Kerszberg M, Changeux JP: A neuronal model of a global workspace in effortful cognitive tasks. Proc. Natl. Acad. Sci. U. S. A. 95, 14529-14534 (1998)

18. Dief AE, Samy DM, Dowedar FI: Impact of exercise and vitamin B1 intake on hippocampal brain-derived neurotrophic factor and spatial memory performance in a rat model of stress. J. Nutr. Sci. Vitaminol. (Tokyo) 61, $1-7(2015)$ 
19. Dietrich A, Audiffren M: The reticular-activating hypofrontality (RAH) model of acute exercise. Neurosci. Biobehav. Rev. 35, 1305-1325 (2011)

20. Enders H, Cortese F, Maurer C, Baltich J, Protzner AB, Nigg BM: Changes in cortical activity measured with EEG during a high-intensity cycling exercise. J. Neurophysiol. 115, 379-388 (2016)

21. Engert F, Bonhoeffer T: Dendritic spine changes associated with hippocampal long-term synaptic plasticity. Nature 399, 66-70 (1999)

22. Fingelkurts AA, Fingelkurts AA (2015): Attentional state: from automatic detection to willful focused concentration. In: Attention and Meaning: The Attentional Basis of Meaning, eds Marchetti G, Benedetti G, Alharbi A, Nova Science Publishers, Hauppauge, pp. 133-150

23. Foley JO, DuBois FS: Quantitative studies of the vagus nerve in the cat. I. The ratio of sensory to motor fibers. J. Comp. Neurol. 67, 49-67 (1937)

24. Frey U, Morris RG: Synaptic tagging and long-term potentiation. Nature 385, 533-536 (1997)

25. Frith E, Sng E, Loprinzi PD: Randomized controlled trial evaluating the temporal effects of highintensity exercise on learning, short-term and long-term memory, and prospective memory. Eur. J. Neurosci. 46, 2557-2564 (2017)

26. Furini CR, Myskiw JC, Schmidt BE, Marcondes LA, Izquierdo I: D1 and D5 dopamine receptors participate on the consolidation of two different memories. Behav. Brain Res. 271, 212-217 (2014)

27. Geva R, Zivan M, Warsha A, Olchik D: Alerting, orienting or executive attention networks: differential patters of pupil dilations. Front. Behav. Neurosci. 7, 145 (2013)

28. Gligoroska JP, Manchevska S: The effect of physical activity on cognition - physiological mechanisms. Mater. Sociomed. 24, 198-202 (2012)

29. Gomez-Pinilla F, Hillman C: The influence of exercise on cognitive abilities. Compr. Physiol. 3, 403-428 (2013)

30. Gutmann B, Zimmer P, Hulsdunker T, Lefebvre J, Binnebossel S, Oberste M, Bloch W, Struder HK, Mierau A: The effects of exercise intensity and post-exercise recovery time on cortical activation as revealed by EEG alpha peak frequency. Neurosci. Lett. 668, 159-163 (2018)

31. Halperin JM: Joggin' for your noggin: the role of physical activity in attention-deficit/hyperactivity disorder. J. Am. Acad. Child Adolesc. Psychiatry. 54, 537-538 (2015)

32. Hansen N: The longevity of hippocampus-dependent memory is orchestrated by the locus coeruleusnoradrenergic system. Neural Plast. 2017, 2727602 (2017)

33. Hansen N, Manahan-Vaughan D: Hippocampal long-term potentiation that is elicited by perforant path stimulation or that occurs in conjunction with spatial learning is tightly controlled by beta-adrenoreceptors and the locus coeruleus. Hippocampus 25, 1285-1298 (2015)

34. Hasselmo ME: The role of acetylcholine in learning and memory. Curr. Opin. Neurobiol. 16, 710-715 (2006)

35. Haynes Iv JT, Frith E, Sng E, Loprinzi PD: Experimental effects of acute exercise on episodic memory function: considerations for the timing of exercise. Psychol. Rep. (2018)

36. Iwamoto GA, Kaufman MP: Caudal ventrolateral medullary cells responsive to muscular contraction. J. Appl. Physiol. (1985) 62, 149-157 (1987)

37. Izumi Y, Zorumski CF: Norepinephrine promotes long-term potentiation in the adult rat hippocampus in vitro. Synapse 31, 196-202 (1999)

38. Kandel ER, Dudai Y, Mayford MR: The molecular and systems biology of memory. Cell 157, 163-186 (2014)

39. Kinomura S, Larsson J, Gulyas B, Roland PE: Activation by attention of the human reticular formation and thalamic intralaminar nuclei. Science 271, 512-515 (1996)

40. Kirk-Sanchez NJ, McGough EL: Physical exercise and cognitive performance in the elderly: current perspectives. Clin. Interv. Aging. 9, 51-62 (2014)

41. Labban JD, Etnier JL: Effects of acute exercise on long-term memory. Res. Q. Exerc. Sport. 82, 712-721 (2011)

42. Laitman BM, John GR: Understanding how exercise promotes cognitive integrity in the aging brain. PLoS Biol. 13, e1002300 (2015)

43. Lemon N, Manahan-Vaughan D: Dopamine D1/D5 receptors gate the acquisition of novel information through hippocampal long-term potentiation and long-term depression. J. Neurosci. 26, 7723-7729 (2006)

44. Leung LS, Shen B, Rajakumar N, Ma J: Cholinergic activity enhances hippocampal long-term potentiation in CA1 during walking in rats. J. Neurosci. 23, 9297-9304 (2003)

45. Li Q, Rothkegel M, Xiao ZC, Abraham WC, Korte M, Sajikumar S: Making synapses strong: metaplasticity prolongs associativity of long-term memory by switching synaptic tag mechanisms. Cereb. Cortex. 24, 353-363 (2014)

46. Loprinzi PD: Intensity-specific effects of acute exercise on human memory function: considerations for the timing of exercise and the type of memory. Health Promot. Perspect. 8, 255-262 (2018) 
47. Loprinzi PD, Edwards MK, Frith E: Potential avenues for exercise to activate episodic memory-related pathways: a narrative review. Eur. J. Neurosci. 46, 2067-2077 (2017)

48. Loprinzi PD, Frith E: A brief primer on the mediational role of BDNF in the exercise-memory link. Clin. Physiol. Funct. Imaging. 39, 9-14 (2018)

49. Loprinzi PD, Frith E: Protective and therapeutic effects of exercise on stress-induced memory impairment. J. Physiol. Sci. (2018)

50. Loprinzi PD, Frith E, Edwards MK, Sng E, Ashpole N: The effects of exercise on memory function among young to middle-aged adults: systematic review and recommendations for future research. Am. J. Health Promot. 32, 691-704 (2018)

51. Loprinzi PD, Herod SM, Cardinal BJ, Noakes TD: Physical activity and the brain: a review of this dynamic, bi-directional relationship. Brain Res. 1539, 95-104 (2013)

52. Loprinzi PD, Kane CJ: Exercise and cognitive function: a randomized controlled trial examining acute exercise and free-living physical activity and sedentary effects. Mayo Clin. Proc. 90, 450-460 (2015)

53. Maletic-Savatic M, Malinow R, Svoboda K: Rapid dendritic morphogenesis in CA1 hippocampal dendrites induced by synaptic activity. Science 283, 1923-1927 (1999)

54. Marzo A, Bai J, Otani S: Neuroplasticity regulation by noradrenaline in mammalian brain. Curr. Neuropharmacol. 7, 286-295 (2009)

55. Matsuzaki M, Honkura N, Ellis-Davies GC, Kasai H: Structural basis of long-term potentiation in single dendritic spines. Nature 429, 761-766 (2004)

56. McGaugh JL: Memory - a century of consolidation. Science 287, 248-251 (2000)

57. McMorris T: Developing the catecholamines hypothesis for the acute exercise-cognition interaction in humans: lessons from animal studies. Physiol. Behav. 165, 291-299 (2016)

58. McMorris T, Davranche K, Jones G, Hall B, Corbett J, Minter C: Acute incremental exercise, performance of a central executive task, and sympathoadrenal system and hypothalamic-pituitary-adrenal axis activity. Int. J. Psychophysiol. 73, 334-340 (2009)

59. McMorris T, Turner A, Hale BJ, Sproule J (2016): Beyond the catecholamines hypothesis for an acute exercise-cognition interaction: a neurochemical perspective. In: Exercise-Cognition Interaction: Neuroscience Perspectives, ed McMorris T, Academic Press, New York, pp. 65-103

60. Mello-Carpes PB, Izquierdo I: The Nucleus of the Solitary Tract $\rightarrow$ Nucleus Paragigantocellularis $\rightarrow$ Locus Coeruleus $\rightarrow$ CA1 region of dorsal hippocampus pathway is important for consolidation of object recognition memory. Neurobiol. Learn. Mem. 100, 56-63 (2013)

61. Mlinar B, Stocca G, Corradetti R: Endogenous serotonin facilitates hippocampal long-term potentiation at CA3/CA1 synapses. J. Neural. Transm. (Vienna) 122, 177-185 (2015)

62. Moncada D, Viola H: Induction of long-term memory by exposure to novelty requires protein synthesis: evidence for a behavioral tagging. J. Neurosci. 27, 7476-7481 (2007)

63. Morcom AM, Bullmore ET, Huppert FA, Lennox B, Praseedom A, Linnington H, Fletcher PC: Memory encoding and dopamine in the aging brain: a psychopharmacological neuroimaging study. Cereb. Cortex. 20, $743-757$ (2010)

64. Neve KA, Seamans JK, Trantham-Davidson H: Dopamine receptor signaling. J. Recept. Signal Transduct. Res. 24, 165-205 (2004)

65. Nikonenko I, Jourdain P, Muller D: Presynaptic remodeling contributes to activity-dependent synaptogenesis. J. Neurosci. 23, 8498-8505 (2003)

66. Ovsepian SV, Anwyl R, Rowan MJ: Endogenous acetylcholine lowers the threshold for long-term potentiation induction in the CA1 area through muscarinic receptor activation: in vivo study. Eur. J. Neurosci. 20, 1267-1275 (2004)

67. Panja D, Bramham CR: BDNF mechanisms in late LTP formation: a synthesis and breakdown. Neuropharmacology 76(Pt. C), 664-676 (2014)

68. Pietrelli A, Matkovic L, Vacotto M, Lopez-Costa JJ, Basso N, Brusco A: Aerobic exercise upregulates the BDNF-serotonin systems and improves the cognitive function in rats. Neurobiol. Learn. Mem. 155, 528-542 (2018)

69. Ponce P, Loprinzi PD: A bi-directional model of exercise and episodic memory function. Med. Hypotheses. 117, 3-6 (2018)

70. Poo MM, Pignatelli M, Ryan TJ, Tonegawa S, Bonhoeffer T, Martin KC, Rudenko A, Tsai LH, Tsien RW, Fishell G, Mullins C, Goncalves JT, Shtrahman M, Johnston ST, Gage FH, Dan Y, Long J, Buzsaki G, Stevens C: What is memory? The present state of the engram. BMC Biol. 14, 40 (2016) 
71. Preston AR, Eichenbaum H: Interplay of hippocampus and prefrontal cortex in memory. Curr. Biol. 23, R764-R773 (2013)

72. Pribram KH, McGuinness D: Arousal, activation, and effort in the control of attention. Psychol. Rev. 82, 116-149 (1975)

73. Rajab AS, Crane DE, Middleton LE, Robertson AD, Hampson M, MacIntosh BJ: A single session of exercise increases connectivity in sensorimotor-related brain networks: a resting-state fMRI study in young healthy adults. Front. Hum. Neurosci. 8, 625 (2014)

74. Richter-Levin G, Akirav I: Amygdala-hippocampus dynamic interaction in relation to memory. Mol. Neurobiol. 22, 11-20 (2000)

75. Roig M, Nordbrandt S, Geertsen SS, Nielsen JB: The effects of cardiovascular exercise on human memory: a review with meta-analysis. Neurosci. Biobehav. Rev. 37, 1645-1666 (2013)

76. Roig M, Thomas R, Mang CS, Snow NJ, Ostadan F, Boyd LA, Lundbye-Jensen J: Time-dependent effects of cardiovascular exercise on memory. Exerc. Sport Sci. Rev. 44, 81-88 (2016)

77. Sajikumar S, Frey JU: Late-associativity, synaptic tagging, and the role of dopamine during LTP and LTD. Neurobiol. Learn. Mem. 82, 12-25 (2004)

78. Sarter M, Gehring WJ, Kozak R: More attention must be paid: the neurobiology of attentional effort. Brain Res. Rev. 51, 145-160 (2006)

79. Segal SK, Cotman CW, Cahill LF: Exercise-induced noradrenergic activation enhances memory consolidation in both normal aging and patients with amnestic mild cognitive impairment. J. Alzheimers Dis. 32, 1011-1018 (2012)

80. Sheynikhovich D, Otani S, Arleo A: Dopaminergic control of long-term depression/long-term potentiation threshold in prefrontal cortex. J. Neurosci. 33, 13914-13926 (2013)

81. Shi SH, Hayashi Y, Petralia RS, Zaman SH, Wenthold RJ, Svoboda K, Malinow R: Rapid spine delivery and redistribution of AMPA receptors after synaptic NMDA receptor activation. Science 284, 1811-1816 (1999)

82. Slipczuk L, Bekinschtein P, Katche C, Cammarota M, Izquierdo I, Medina JH: BDNF activates mTOR to regulate GluR1 expression required for memory formation. PLoS One 4, e6007 (2009)

83. Sng E, Frith E, Loprinzi PD: Temporal effects of acute walking exercise on learning and memory. Am. J. Health Promot. 32, 1518-1525 (2018)

84. Snyder GL, Fienberg AA, Huganir RL, Greengard P: A dopamine/D1 receptor/protein kinase A/dopamine- and cAMP-regulated phosphoprotein $(\mathrm{Mr} 32 \mathrm{kDa}$ )/protein phosphatase-1 pathway regulates dephosphorylation of the NMDA receptor. J. Neurosci. 18, 10297-10303 (1998)

85. Stanton PK, Sarvey JM: Depletion of norepinephrine, but not serotonin, reduces long-term potentiation in the dentate gyrus of rat hippocampal slices. J Neurosci. 5, 2169-2176 (1985)

86. Sutoo D, Akiyama K: Regulation of brain function by exercise. Neurobiol. Dis. 13, 1-14 (2003)

87. Takeuchi T, Duszkiewicz AJ, Morris RG: The synaptic plasticity and memory hypothesis: encoding, storage and persistence. Philos. Trans. R. Soc. Lond. B Biol. Sci. 369, 20130288 (2014)

88. Tsujii T, Komatsu K, Sakatani K: Acute effects of physical exercise on prefrontal cortex activity in older adults: a functional near-infrared spectroscopy study. Adv. Exp. Med. Biol. 765, 293-298 (2013)

89. van Dongen EV, Kersten IH, Wagner IC, Morris RG, Fernandez G: Physical exercise performed four hours after learning improves memory retention and increases hippocampal pattern similarity during retrieval. Curr. Biol. 26, 1722-1727 (2016)

90. Wang GJ, Volkow ND, Fowler JS, Franceschi D, Logan J, Pappas NR, Wong CT, Netusil N: PET studies of the effects of aerobic exercise on human striatal dopamine release. J. Nucl. Med. 41, 1352-1356 (2000)

91. Wang Z, Myers KG, Guo Y, Ocampo MA, Pang RD, Jakowec MW, Holschneider DP: Functional reorganization of motor and limbic circuits after exercise training in a rat model of bilateral parkinsonism. PLoS One 8 , e80058 (2013)

92. Weinberg L, Hasni A, Shinohara M, Duarte A: A single bout of resistance exercise can enhance episodic memory performance. Acta Psychol. (Amst). 153, 13-19 (2014)

93. Winder DG, Martin KC, Muzzio IA, Rohrer D, Chruscinski A, Kobilka B, Kandel ER: ERK plays a regulatory role in induction of LTP by theta frequency stimulation and its modulation by beta-adrenergic receptors. Neuron 24, 715-726 (1999)

94. Winter B, Breitenstein C, Mooren FC, Voelker K, Fobker M, Lechtermann A, Krueger K, Fromme A, Korsukewitz C, Floel A, Knecht S: High impact running improves learning. Neurobiol. Learn. Mem. 87, 597-609 (2007) 